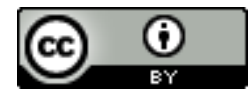

Esta obra está sob o direito de Licença Creative Commons Atribuição 4.0 Internacional.

\section{NOVAS TECNOLOGIAS E PRÁTICA DE ENSINO: DESAFIOS PARA O PROFESSOR DA ERA DIGITAL}

\author{
Luciane Victorino Barbosa ${ }^{1}$ \\ Joselito Araújo Silva ${ }^{2}$
}

\section{RESUMO}

Este artigo apresenta uma exposição teórica sobre a história das gerações, uma reflexão sobre as vantagens do uso das novas tecnologias na prática de ensino bem como uma crítica sobre os perigos do uso livre da internet no espaço escolar. Problematiza a prática pedagógica de professores que se encontram presos aos métodos tradicionais e sentem medo de inovar. Tem como principais objetivos discutir ideias, métodos e apresentar sugestões que ajudem o professor a tornar sua aula mais atrativa. Os resultados sugerem que a prática pedagógica deve ser aliada das novas tecnologias. Nesse sentido considera-se que o professor deve vencer os desafios da era digital e que a escola precisa se integrar com o mundo que a cerca.
\end{abstract}

Palavras-chave: Novas tecnologias. Prática de ensino. Era digital.

\begin{abstract}
This article presents a theoretical exposition on the history of generations, a reflection on the advantages of using new technologies in teaching practice, as well as a criticism about the dangers of free use of the internet in the school space. It questions the pedagogical practice of teachers who are stuck with traditional methods and are afraid to innovate. Its main objectives are to discuss ideas, methods and make suggestions that help the teacher to make his class more attractive. The results suggest that pedagogical practice should be combined with new technologies. In this sense, it is considered that the teacher must overcome the challenges of the digital age and that the school needs to integrate with the world around it.
\end{abstract}

Keywords: New technologies. Teaching practice. Digital age.

\footnotetext{
${ }^{1}$ Lucianebarbosa06@hotmail.com

2 joselitoaraujo947@gmail.com
} 
Rev. Científica Evidência, Maceió, v. 3, n.1, p. 125-136, out/dez, 2020

\section{INTRODUÇÃO}

A pesquisa apresenta um breve resumo da história das gerações bem como suas características, que discute mudanças na prática de ensino e a quebra de paradigmas por parte de profissionais que receiam inovar suas aulas. $\mathrm{O}$ estudo ainda aborda o perigo do uso livre da mais importante ferramenta tecnológica da atualidade, a internet. Procura mostrar que quando usada no contexto escolar com responsabilidade pode ser um objeto facilitador da aprendizagem e rica fonte de pesquisas.

Ao dividir os indivíduos em grupos, pode-se classificá-los por geração, a cada geração que surge, há superação da outra em questão de descobertas e conquistas. (Fava 2012) Cada grupo entende que sua geração é a mais avançada, é única, é mais competente que as anteriores. Quando existe um contato diário, rotineiro entre pessoas de idades diferentes, ou quando essa convivência se passa no espaço escolar, não havendo uma abertura de pensamentos, pode haver conflitos.

Em relação ao aprimoramento do processo de ensino, sugere-se uma reflexão por parte do profissional da educação, que este reveja sua postura, enquanto educador na era digital. Pois sua clientela faz parte de uma geração que está sempre conectada e também está apenas a um clique das informações que desejam. Nada pode ser monótono. Os jovens são seguros de si e sabem o que querem. Podem acatar sugestões, mas não aceitam imposições ou normas ditadas.

Esse estudo ainda aborda os perigos do uso livre da internet no espaço escolar e sugere alguns cuidados por parte dos pais e da escola em relação a esse problema. A internet representa uma das grandes conquistas da humanidade, que deu ao homem uma certa onipresença e lhe abriu portas para grandes oportunidades. Novos empregos surgiram e aparece uma nova forma de expor a arte ao mundo. Mas os perigos são inegáveis.

Estamos vivendo a Era Digital e os jogos, as doenças, os vícios, a pornografia, os prejuízos financeiros, o suicídio, principalmente entre os jovens, são os pontos negativos desse período. $\mathrm{O}$ surgimento de novas doenças causadas pelo uso constante e doentio dessa ferramenta digital é um ponto negativo, que se contrapõe aos inúmeros benefícios trazidos por ela ao mundo contemporâneo; Por isso, a pesquisa apresenta discussões e sugestões de prudência em relação à utilização da rede. 
Rev. Científica Evidência, Maceió, v. 3, n.1, p. 125-136, out/dez, 2020

\section{METODOLOGIA}

Trata-se de uma revisão de literatura tradicional, não sistemática, descritiva, de

\section{RESULTADOS E DISCUSSÕES}

\section{Nomenclatura e características das} gerações

As gerações são grupos de pessoas que pertencem à mesma faixa etária. Os estudiosos as classificam de acordo com o ano em que nasceram, os hábitos que possuem e o momento, que faz parte da formação de sua personalidade. Existe uma razão social para que determinado grupo de pessoas tenha sua própria forma de agir. Seus medos, seus anseios, suas manias, são frutos do contexto histórico em que se vive. A sociedade de cada época exerce influência direta no comportamento de cada geração.

\section{Geração belle époque}

Uma das gerações mais próximas da era em que vivemos é a chamada de Belle Époque brasileira, ou seja, as pessoas que nasceram, segundo (Oliveira 2008), entre 1920 e 1940. Os teatros, as livrarias, os cafés-concertos, as operetas e os balés da França encantavam e seduziam os brasileiros, que tinham condições de ostentar uma viagem por ano a Paris, que naquela época era de profundo bom tom que se visitasse. natureza qualitativa, com análise de conteúdo de livros e documentos adquiridos em bibliotecas físicas e virtuais.

Segundo (OLIVEIRA, 2008) a missão dos jovens dessa geração era reconstruir a sociedade, e isso os influenciou positivamente na formação de suas famílias, na educação de seus filhos e no trabalho. Por isso, os costumes dessa época eram bem diferentes dos costumes atuais. As famílias tinham outros valores. Não havia a liberdade e o respeito às diferenças que existe hoje em dia.

Infelizmente, a educação neste período era para poucos. A elite brasileira era a minoria e somente ela tinha acesso a uma educação de qualidade. A carreira militar foi tudo o que sobrou como opção para a classe média que quase não existia. $\mathrm{O}$ poder estava nas mãos dos latifundiários e a industrialização dava seus primeiros passos. Com a Primeira Guerra mundial, alguns jovens que podiam estudar com bastante dedicação, assim o faziam.

Atualmente, como a média de vida dos brasileiros aumentou, ainda há pessoas dessa faixa etária, mas como aposentados, evidente que não atuam mais nas salas de aula, numa convivência diária com os jovens. Se exercem alguma influência na prática de algum professor em exercício da função, está se dá de forma indireta, pela 
convivência familiar ou pelo legado de suas vidas enquanto professores atuantes.

\section{Geração baby boomer}

Com o fim da Segunda Guerra Mundial as pessoas tentavam reconstruir suas vidas e o brasileiro decidiu ter mais filhos. De acordo com Oliveira (2008), pertencem à geração "Baby Bommer" os nascidos entre 1940 e 1960. Foi a primeira geração a viver um período significativo de paz. Surgem então os Anos Dourados. Foram muitos bem assistidos pelos pais e criaram uma visão positiva do amor. A educação era rígida e havia severas punições para comportamento fora do padrão.

A classe média emergente teve acesso à universidade. Doutrinas e dogmas foram questionados. A liberdade que o jovem tinha para questionar criou um clima de rebeldia. $\mathrm{O}$ amor livre, sexo, drogas. Os Baby Boomers foram conquistadores da liberdade tão almejada. Eles eram idealistas e sonhavam com um mundo salvo pelo amor. Faziam oposição ao consumismo, usavam roupas velhas e adotavam um estilo hippie. Praticavam nudismo e consumiam muita droga.

O estilo musical era o rock psicodélico de Led Zeppelin, Jimi Hendrix, Pink Floyd, Bob Dylan, The Beatles e Janis Joplin. No Brasil, Raul Seixas, Mutantes, Zé Ramalho, Caetano Veloso e Gilberto Gil inspiravam posturas e comportamentos de questionamentos e insatisfação com o que ditava as elites dominantes. Segundo (OLIVEIRA, 2008), eles já em idade madura, começaram a se preocupar com o bem estar e com a saúde, atualmente ainda conservam essa preocupação, no objetivo de conseguirem estar eternamente jovem.

No final de 1960 e início de 1970, os Baby Boomers, com uma parte do idealismo perdido por causa de grandes acontecimentos como o assassinato de John Kennedy e de Martin Luther King, mergulharam no mundo do trabalho e passaram a planejar melhor suas vidas. Atualmente, já amadurecidos, os lbaby Boomers são considerados os pais da geração $\mathrm{X}$, avós da geração Y e bisavós da geração Z. Muitos se aposentaram cedo e voltaram para o mercado de trabalho.

\section{A geração $x$}

Essa geração aproveita a liberdade conquistada por seus pais. Procura viver o materialismo, o consumismo, querem viver o hoje e confiam o mínimo no dia de amanhã. A geração dos nascidos entre 1960 e 1980 segundo Oliveira (2008), é denominada Geração " $X$ ”. Trata-se de uma geração inconformada e competitiva. A geração $X$ é bem individualista. Muitos conviveram em famílias desfeitas pelo divórcio.

A geração X é muito confiante em si mesmo e pouco confiante na sociedade. 
Está cada vez mais especializada em tecnologia. São interessados por tudo, mas de maneira superficial. Segundo (OLIVEIRA, 3008), alguns ainda fizeram parte de movimentos como hippies. Mostravam roupas coloridas. Ouviam músicas mais barulhentas, tudo era excesso. Eram considerados rebeldes e não toleravam nada convencional ou padronizado, inclusive a família.

A primeira vista é alguém atraente, dinâmico e divertido, mas sendo melhor observado, é materialista, egoísta, vazio e contraditório. Nem religioso, nem ateu, tem sua própria perspectiva. Visa dinheiro, poder e fama, então sua visão de ética em que se aderir à sua própria medida. Felizmente está cansado e esse cansaço cede espaço para que ele próprio perceba que precisa criar um espaço afetivo onde caiba o material, o espiritual e o cultural. É uma geração angustiada por vários conflitos, entre eles o fato de ter uma constante crise de identidade entre $\mathbf{o}$ materialismo e o espiritualismo.

Essa geração, sempre apressada, é também uma geração estressada e por isso causa em seus filhos um comportamento indisciplinado nas escolas que frequentam. É uma geração que reconhece que para ter melhor emprego, é preciso ter novas habilidades, informações e aprendizados. A geração $\mathrm{X}$ estabeleceu um novo código de relacionamento e comportamento. A consequência foi o declínio das relações familiares.

Todos esses aspectos da geração $\mathrm{X}$ influenciaram a geração $\mathrm{Y}$, de modo que aliada à tecnologia e ao mundo digital, incentivou a formação de uma geração que é ousada, agressiva, não gosta de admitir erros e costuma atormentar os profissionais da área da educação que interagem com ela. A maioria dos professores atuantes em sala de aula faz parte dessa geração e geralmente, pelo choque de opiniões, entram em conflito com seus alunos.

\section{Geração y}

A denominada Geração "Y", segundo Oliveira (2008), são os nascidos entre 1980 e 1999, são filhos dos Baby Bommers e dos primeiros membros da Geração "X". Trata-se de uma geração que tem um comportamento diferente de todas as outras gerações. É uma geração realista, são consumistas ao extremo, têm como ídolos pessoas próximas. Alguns a apontam como a geração daqueles que consomem álcool e drogas em excesso, uma geração triste e superprotegida.

São diferentes porque são jovens, que cresceram num mundo digital. Eles têm sede de informação, amam o excesso. Segundo (PERISCINTO, 2008) é normal essa geração usar o celular, ou alguma rede social, ao mesmo tempo em que comem algo, possuem habilidade para equilibrar 
diversas atividades, mas sentem dificuldade de concretizar um projeto a longo prazo. Eles têm algo em comum que é o tempo excessivo em que passam conectados.

Passam muito tempo sem diferenciar o que online e o off-line. Eles não pensam na identidade digital e real separadamente. Eles estão a apenas um clique daquilo que procuram. Eles nem usam relógio porque estão online ininterruptamente. Eles possuem hábitos eletrônicos no sentido de acessar o facebook, pesquisar no google, usar o instagram, escolher seu filme preferido no Netflix, ou baixar sua música preferida no shared.

Eles podem auxiliar membros de outras gerações com pesquisas e atualizações. Preferem arquivos digitais a livros, e-mails a cartas, vivem em redes de relacionamento, compartilham tudo, expõem seus sentimentos online. Este jeito de viver é motivo de preocupação para os educadores da contemporaneidade. Eles se expõem em excesso. Do ponto de vista dos membros de outra geração, algumas exposições mais íntimas podem comprometer o futuro profissional ou pessoal destes jovens.

Mas eles não compreendem a dimensão do perigo, porque ciberespaço em que vivem não permite. Parece que existe uma falha de comunicação entre eles e seus professores, que não entendem sua linguagem e não aceitam tantas abreviações. Hoje, baseado na forma de comunicação desses jovens, pode-se dizer que há risco de um declínio de uma linguagem culta formal. Alguns professores não aceitam a linguagem utilizada pelos jovens da geração $\mathrm{Y}$.

\section{Geração z e geração alpha}

A Geração Z e a Geração Alpha são compostas por pessoas que possuem certa dependência da tecnologia. Elas nasceram na era dos tablets, smartphones, internet banda larga, jogos eletônicos e todo esse aparato tecnológico faz parte de suas vidas.

A geração " $Z$ ”, para (Peconick, 2012) costuma zapear, capazes de mudar com rapidez da TV para o celular, do videogame para uma rede social ou do MP4 para o e-book. Elas têm o mundo 2.0 no DNA.

Em relação à Geração Alpha, não existem muitas definições sobre ela, a qual é composta por pessoas, que nasceram após o ano de 2010 e que ingressaram na escola mais cedo, assim armazenam um número de informações maior do que as gerações anteriores, pois nasceram e estão vivendo num período rico em informações lançadas pelos meios de comunicação de massa e sites disponíveis na internet à distância de um clic. 
Uma reflexão sobre a prática pedagógica na era digital

$\mathrm{O}$ acesso às novas tecnologias transformou a humanidade. Hoje, os indivíduos, em suas relações digitalizadas, são transformados em seres consumidores geradores-disseminadores de informações, abrindo espaço para a construção da subjetividade. Tudo isso pela experiência da inter-relação que acontece através das redes sociais. (ALVES \& MANCEBO, 2006). Por isso que as pessoas são mais criativas, possuem rápido raciocínio, são hábeis pesquisadoras e estão sempre disponíveis às novas descobertas.

A convivência entre discentes e docentes no interior da escola, mais precisamente na sala de aula nem sempre é fácil, nesse período em que o mundo exige uma mudança de postura, por parte do profissional da educação, que tenciona obter sucesso em sua prática pedagógica. São pessoas de gerações diferentes, com valores diferentes e hábitos diferentes convivendo em meio ao risco de vivenciarem uma prática rotineira, repetitiva ou até mesmo cansativa para os mais jovens.

Diante das inovações que as novas tecnologias impuseram na vida humana, no contexto social e familiar, a escola não pode ficar alheia a essas mudanças. Em suas casas, os alunos têm acesso a grande parte do que as ferramentas tecnológicas podem oferecer. As tecnologias da informação, também chamadas de midiáticas, como: televisões, computadores, celulares, presentes no cotidiano das pessoas. Entretanto, alguns professores ainda se prendem ao passado adotando uma aversão ao uso das novas TICS.

A escola precisa ser a continuação da casa de seus alunos. Ela precisa oferecer espaço para o aluno desenvolver sua subjetividade. Dessa forma, um dos desafios da escola atual e dos professores, como afirma Kenski é "desenvolver a consciência crítica e fortalecer a identidade das pessoas e dos grupos" (KENSKI, 2009, p. 26). Portanto, o profissional que se recusa a acompanhar as inovações tecnológicas, corre o risco de comprometer seu trabalho. Através das tecnologias, as aulas podem ficar mais interessantes. É o fim do modelo em que no topo está o professor, muitas vezes numa posição arrogante e desagradável para o aluno, que por sua vez deveria ser receptor passivo de um conhecimento transmitido, ditado. Ensinar com as novas mídias será uma revolução, se mudarmos simultaneamente os paradigmas convencionais do ensino, que mantêm distantes professores e alunos. (MORAN, 2009).

Não é raro atualmente, mesmo nas escolas que possuem recursos tecnológicos, alguns professores ainda permanecerem em modelos tradicionais de aulas onde não hã 
uso das tecnologias. É necessário, portanto inserir o uso das TICs no ensino, pois isso poderá mudar o papel do educador de ‘transmissor de informação' para mediador na construção do conhecimento, provocador de situações, considerando ainda a referência do aluno (ALVES, 2009).

Há algum tempo, muito se afirmava em relação à oferta das novas tecnologias nas escolas públicas. Dizia-se muito que as elites dominantes cobravam do professor o uso das tecnologias nas salas de aula, mas tudo na realidade era muito diferente. O tempo passou rápido e com ele vieram o princípio das mudanças, porque aos poucos as novas tecnologias invadiram a escola e também a nossa sociedade.

É necessário abraçar os desafios, o professor precisa reaprender a ensinar. Precisa aprender a interagir com a geração com a qual convive em suas aulas. Mas infelizmente velhas concepções e velhas práticas ainda persistem nos espaços de ensino. Seja no virtual ou no presencial. (BEZERRA, 2010), esse tipo de profissional, constantemente acusa seus alunos de indisciplina, sem querer admitir as causas que levam esses jovens a serem "indisciplinados".

Atualmente, muitas pesquisas de caráter científico e acadêmico são realizadas no sentido de investigar como anda o uso das tecnologias nas escolas públicas brasileiras, a infraestrutura que a escola oferece, o uso do computador, as principais barreiras que impedem a utilização, ou os motivos que impedem o professor a ser um adepto do emprego das novas tecnologias em sua prática pedagógica. (ALMEIDA, 2014).

O uso das TICS na educação visa aprimorar à aprendizagem, possibilitar aos profissionais melhores resultados no trabalho e tornar o aluno mais independente, responsável por administrar o tempo de estudo, organizar conteúdos, mesmo quando não estão em casa ou na escola. (KENSKI, 2007). Dessa forma pode se abrir caminhos para novas possibilidades também na carreira do professor, uma vez que o docente ao avaliar o aluno, automaticamente está sendo avaliado.

\section{O perigo do uso livre da internet nas escolas públicas}

Tudo o que é novo encanta, fascina. A internet banda larga já é uma realidade em algumas escolas públicas do Brasil. Governantes decidiram ofertar internet para as escolas e isso é uma conquista extremamente positiva. A facilidade com que se pode fazer uma pesquisa é algo que não se podia nem sonhar a alguns anos atrás. Plataformas digitais, sites mundialmente conhecidos, redes sociais que divertem e integram.

A internet deve ser usada com responsabilidade e por quem está preparado 
para fazê-lo. Conforme Borges (2013) "muito se discute sobre os eventuais benefícios ou malefícios às crianças e adolescentes decorrentes do uso da Internet.

No Brasil, a preocupação justificase pelo número crescente de acesso destes jovens à rede mundial de computadores". Na verdade, nada é completamente bom ou ruim, cabe às pessoas usarem do bom senso.

Os riscos do uso livre da internet são um problema mundial e preocupa o mundo inteiro por perigos tais como o cyberbullying; muito grave e comum nas escolas entre os adolescentes que quando vítimas ficam expostos, no seu círculo de conhecimento; perda de privacidade, perda de segurança, recepção de material pornográfico, ser vítimas de fraudes online, aliciamento para jogos com dinheiro online.

Há outros perigos, como vírus, troianos, phishing, spyware. No espaço escolar, tudo pode ser acessado se não houver algumas medidas de segurança. (COMISSÂO EUROPÉIA, 2008).

Alguns jovens desconhecem tanto o perigo do uso indevido da internet, que publicam fotos sem autorização de colegas, sem saber que isso é crime. Outros se envolvem em jogos que os leva a atitudes alarmantes, como o suicídio. Outros ainda são atraídos para locais ermos ao encontro de desconhecidos e acabam sendo vítimas de estupro ou até mesmo de assassinatos. Como afirma Almeida \& Prado:
[...] para evitar ou superar o uso ingênuo dessas tecnologias, é fundamental conhecer as novas formas de aprender e de ensinar, bem como de produzir, comunicar e representar conhecimento, possibilitadas por esses recursos, que favoreçam a democracia e a integração social. (ALMEIDA \& PRADO, 2006).

Afinal, os perigos do uso da internet, e de forma específica, das redes sociais existem não apenas para os adolescentes na escola, mas para as pessoas de qualquer idade, e o professor também deve se policiar em relação ao aceso livre da internet, mesmo considerando que essa prática favoreça sua convivência na sociedade e o torne um cidadão do mundo contemporâneo.

Por isso, as formações continuadas são tão importantes para o professor. Elas podem fazer do profissional alguém capaz de superar dificuldades, um ser aberto às mudanças. Através destes cursos, o professor se habilita, se atualiza e interage com os companheiros de trabalho, trazendo suas dificuldades para o debate e compartilhando seus conhecimentos. Os órgãos públicos e privados devem oferecer, mas o profissional também tem que buscar.

Não dá para imaginar a vida corrida, os compromissos, os cursos frequentados, os trabalhos feitos, as novas profissões, que surgem neste mundo contemporâneo sem o uso das novas tecnologias. Segundo Souza “[...] o computador pode ser utilizado em 
proveito de um novo encantamento na escola, com múltiplas e diferenciadas possibilidades de ações" (SOUZA, 2004, p. 103). Na ciência, nas construções, de modo que o mundo mudou e as pessoas também.

A revolução da internet, as novas formas de organização social, os novos conceitos de família, virtual e em rede, o novo espaço imaginário vivido como real, o

\section{CONSIDERAÇÕES FINAIS}

O estudo foi feito em forma de pesquisa bibliográfica visando discussões e reflexões onde constatou-se que com o crescente avanço tecnológico não se pode negar a necessidade de implantação das novas tecnologias de informação e comunicação na escola. Verificou-se também que existe uma certa aversão ao uso das novas tecnologias na metodologia de ensino, por parte de alguns profissionais, que não têm afinidade com as ferramentas digitais, por não terem se adaptado ainda às mudanças da era atual.

Foi visto que alguns professores chegam a transferir a culpa da reprovação ou da falta de interesse de seus alunos à indisciplina. Os conflitos acontecem pelo fato de o aluno não conseguir ficar passivo, sentado e ouvinte. Enquanto isso, esses educadores não admitem mudanças e gostariam que seus alunos fossem receptivos, obedientes e não opinantes. Os conflitos entre a geração dos professores, ciberespaço. Todas essas mudanças têm provocado alterações no comportamento de todas as gerações, que se encontram vivenciando a era digital. (COSTA, 2002), mudanças positivas vinculadas aos avanços e descobertas e mudanças negativas vinculadas aos problemas que os excessos podem causar.

geralmente da geração X e dos seus alunos, a maioria da geração Y nesse contexto, são inevitáveis.

Entretanto foi visto também que muito se cobra do professor, mas pouco se oferece. A necessidade de formação continuada feita por profissionais habilitados, que possam sanar dúvidas e preparar o professor para um trabalho de qualidade é imprescindível. Os professores consideram a necessidade de cursos de formação que lhes ofereçam meios de vivenciar experiências, que aprimorem suas capacidades técnicas e pedagógicas.

A pesquisa constatou ainda que a internet deve ser usada com limitação e responsabilidade, no espaço escolar, por causa da exposição aos perigos que esta fonte de informações oferece. Isso não deve atrapalhar o uso das novas tecnologias. Muitas escolas já possuem laboratórios de informática equipados. São muitas possibilidades de ações positivas, que podem enriquecer a prática pedagógica, com o uso das ferramentas digitais em sala de aula. 
A internet, que encanta no primeiro momento, pode ser uma ameaça se não se está preparado para se utilizar. Constituição psíquica dos homens, mulheres e crianças dos nossos dias não têm o mesmo comportamento das pessoas de alguns anos atrás. A mudança que a revolução das novas tecnologias e em especial da internet tem provocado mudanças externas na sociedade e, também, no interior das pessoas.

\section{REFERÊNCIAS}

AlVES, P.; MANCEBO, D. Tecnologias e Subjetividade na Contemporaneidade, Estudos de Psicologia, v. 11, n.1, p. 4552, 2006.

ALMEIDA. F. J., FRANCO, M. G. Tecnologias para a Educação e Políticas Curriculares de Estado. In: TIC e Educação 2013. Pesquisa sobre o uso das Tecnologias de Informação e Comunicação nas escolas brasileiras - ICT Education, 2013. 2014.

BEZERRA, Márcia Alves. Docência em educação a distância: tecendo uma rede de interações. Dissertação do EDUMATEC. Recife. O Autor, 2010, 190 f.

BORGES, DONALDO DE ASSIS.

Crianças e Adolescentes na Internet: a responsabilidade dos pais ou responsáveis. 2013. Disponível em: < http://meuartigo.brasilescola.com/educacao /criancas-adolescentes-naInternetresponsabilidade.htm>. Acesso em: 26 nov. 2013.

Comissão Europeia. Safety tips. Retirado em 31 de Dezembro de 2008, de
Portanto, é papel da escola utilizar as novas tecnologias no cotidiano, aplicando numa perspectiva interdisciplinar. Mas adotar filtros ou programas que limitem o acesso livre à internet é bastante pertinente, dado os perigos que o uso livre dessa ferramenta pode oferecer. As instituições escolares precisam adotar uma política séria, pois seu uso no espaço escolar só cabe como ferramenta de aprendizagem.

http://ec.europa.eu/information_society/act ivities/sip/ safety_tips/index_en.htm

FAVA,. EDUCAÇÃO 3.0: como ensinar estudantes com culturas tão diferentes. Cuiabá: Carline \& Caniato. Editorial (nome de fantasia da editora Tanta Tina Ltda).

KENSKI, Vani Moreira. Educação e Tecnologias: O novo ritmo da informação. São Paulo: Papirus, 2007.

MORAN, José Manuel. Novas

Tecnologias e Mediação Pedagógica.

Campinas, SP: Papiorus,2001.

MCCRINDLE, M. The ABC of the XYZ: Understanding global Generations.

Sydney: UNSW Press, 2011.

OLIVEIRA, Sidney. Geração Y Era das Conexões - Tempo de relacionamentos. São Paulo: Clube dos Autores, 2008.

PERISCINOTO, A. Geração Y chega à liderança, 2008.

Disponível em: < htpp:www academia do futuro.com / >. Acesso em: 06 jul. 2009

PECONICK, A. Vem aí geração Z. 2012. 
Disponível em:

<http://www.grupolet.com/noticias_20120

924_Geracao\%20Z.asp>. Acesso em: 4 maio 2013.

SOUZA, C. A. Investigação-ação escolar e resolução de problemas de física: $o$ potencial dos meios tecnológicocomunicativos. 2004. 295 f. Tese (Doutorado em Educação) - Universidade Federal de Santa Catarina, Florianópolis, 2004. 